\title{
WHAT ARE THE CHARACTERISTICS DEFINING FLYER-PRONE CONSUMERS? A THEORETICAL AND EMPIRICAL ANALYSIS
}

\author{
Juan Carlos Gázquez-Abad, University of Almería, Spain \\ Francisco J. Martínez-López, University of Granada and Open University of Catalonia, Spain \\ Manuel J. Sánchez-Franco, University of Seville, Spain
}

\begin{abstract}
The investments on sales promotions in the USA and many European countries has considerably increased over the last years. In particular, the weekly advertising of price reductions in store flyers is a frequently used promotional tool in retail business. Stores typically use store flyers to promote new products, announce new stores, and communicate price specials. Other types of promotion (for example, coupons) can also be included, but this is not frequent. In most cases the offers are 'perishable' - i.e., their utility is limited to a particular period of time (such as a week or two).
\end{abstract}

The increasing use of store flyers is due, in part, to the fact that they provide a quicker response than traditional advertising media. Store flyers also allow retailers to include more product categories and brands, if compared with the case of traditional advertising media, as well as enabling distributors to emphasise their own brands. Moreover, advertising promotions in store flyers are a source of revenue for distributors from fees charged to manufacturers whose brands appear in them.

The main objective of this study is to characterise the 'flyer-proneness' of consumers by an analysis of the consumer-level characteristics. In particular, the study aimed at predicting the differences between consumers highly prone and less prone to store flyers in terms of their sensitivity to three types of variables: (i) economic variables; (ii) shopping-related variables, and (iii) demographic aspects. Both the popular business press and prior promotional literature suggest that these variables may be related to consumers' level of proneness toward store flyers.

Data for this study were obtained from a survey aimed to people who buy all or part of the package food and cleaning products for the home. The survey was carried out in several retail stores (hypermarkets, supermarkets and discounts) in the metropolitan area of a Spanish city.

The results of this paper confirm some of the previous results related to deal proneness in general. Nevertheless, there are some aspects that somehow differ from those results obtained in studies developed for other promotional tools in other contexts.

Thus, our results show that consumers highly prone to consult store flyers are not worried about the price they pay. Given the greater costs involved in the simultaneous use of store flyers and price deals, managers can thus reduce their promotional cost by including brands in flyers without an accompanying price reduction. In addition, flyer-prone consumers enjoy reading store flyers because it makes them feel like smart shoppers. It seems, therefore, that consumers perceive store flyers as a sign of potential savings, even if, as previously commented, there is no actual price reduction. Given the credibility that customers pay to information contained in store flyers, all those aspects related to the designing and structure of such flyers can be considered as a key element in the communication strategy of marketers.

Taken together, our findings support the 'domain specificity' of the deal-proneness construct shared by many authors. Because the same group of variables might influence consumer proneness in a different way depending on the promotional type under study, our results support the 'domain specificity' point of view. Hence, it is important to individually analyse the relationship between such variables and the promotion-type specific proneness of consumers.

References available upon request 